\title{
Avaliação retrospectiva dos testes de toxicidade inespecífica realizados no Instituto Nacional de Controle de Qualidade em Saúde em produtos biológicos
}

\section{Retrospective evaluation of unspecific toxicity tests performed at the National Institute for Quality Control in Health on biological products}

\author{
Lilia Serodio',* (iD \\ Cristiane Caldeira ${ }^{1, I I}$ iD \\ Carolina Oliveira ${ }^{\text {I,I }}$ iD \\ Elias de Jesus',11 iD \\ Wlamir Moura ${ }^{1,11}$ iD \\ Octavio Presgrave ${ }^{1, I I}$ iD
}

\begin{abstract}
RESUMO
Introdução: 0 teste de toxicidade in vivo, conhecido como teste de toxicidade inespecífica (TTI), é sugerido para avaliar a segurança de produtos biológicos e derivados de biotecnologia. 0 princípio do teste é a administração do produto em animais, seguido por um período de observação. O Instituto Nacional de Controle de Qualidade em Saúde (INCQS) é o laboratório de controle nacional brasileiro (LCN) que controla os produtos biológicos, especialmente vacinas e soros hiperimunes, para o Programa Nacional de Imunização (PNI) antes da liberação para o mercado. São preconizados ensaios químicos, microbiológicos e toxicológicos, inclusive o TTI. Objetivo: Analisar retrospectivamente o TTI realizado no INCQS e verificar as monografias da Farmacopeia Brasileira onde ainda é preconizado o teste. Método: Foi realizado um levantamento no sistema de dados Harpya do INCQS, para verificar os resultados satisfatórios e insatisfatórios do TTI. Resultados: No período de 1999 a 2012, foram realizados $3.453 \mathrm{TTI}$ nos produtos biológicos, resultando em $100 \%$ de resultados satisfatórios. Com base nestes resultados e seguindo a tendência mundial, o INCQS vem desde 2002 reduzindo gradualmente a quantidade de produtos biológicos submetidos ao TTI. Atualmente, o risco de contaminação de produtos farmacêuticos com substâncias não específicas é significativamente baixo, pois as indústrias são reguladas para o cumprimento das boas práticas de fabricação (BPF). Embora o TTI ainda permaneça nos Testes Gerais da Farmacopeia Brasileira, ele não é requerido nas monografias específicas de soros hiperimunes e vacinas para uso humano. Conclusões: 0 TTI não parece ser eficiente para detectar toxicidade inespecífica em biológicos e o Brasil deve seguir a tendência mundial de interromper a sua execução.
\end{abstract}

PALAVRAS-CHAVE: Toxicidade Inespecífica; Controle de Qualidade; Vacinas; Soros Hiperimunes

\section{ABSTRACT}

Introduction:The in vivo toxicity test known as Unspecific Toxicity Test (ITT) is recommended to assess the safety of biological products and biotechnology derivatives. The principle of this test is the administration of the product in guinea pigs and mice, followed by an observation period. INCQS is the Brazilian National Control Laboratory (NCL) that works controlling biological products, especially vaccines and hyperimmune sera for the Immunization National Program (INP) before going to market. Chemical, microbiological and toxicological tests are performed, including ITT. Objective: To analyze the ITT performed at INCQS and to verify the monographs of the Brazilian Pharmacopeia where the test is still recommended. Method: A survey was carried out with the Harpya data system, which is used to record all samples and analyses. Results: From 1999 to 2012, 3,453 ITT were performed on biological products, resulting in 100\% negative results. Based on these results and following a worldwide trend, since 2002 INCQS has been gradually reducing the amount of vaccines and hyperimmune sera submitted to the 
unspecific toxicity test. Currently, the risk of contamination of pharmaceutical products with non-specific substances is significantly low, as industries are regulated to comply with Good Manufacturing Practices (GMP). Although ITT still remains in the General Tests of the Brazilian Pharmacopoeia, it is not required in specific monographs of hyperimmune sera and vaccines for human use. Conclusions: These results show that ITT appears to be not enough efficient for detecting nonspecific toxicity due to biological products manufacture and Brazil may follow the worldwide trend to stop performing it.

KEYWORDS: Unspecific Toxicity; Quality Control; Vaccines; Hyperimmune Sera

\section{INTRODUÇÃO}

0 teste de toxicidade in vivo, também conhecido como teste de toxicidade inespecífica (TTI), é sugerido para a avaliação da segurança de produtos biológicos e derivados de biotecnologia. O princípio desse ensaio consiste na administração de um volume específico do produto em dois cobaios e cinco camundongos, seguido por um período de observação. Um produto é classificado como conforme se, após 7 dias do início do teste, todos os animais sobreviverem e não manifestarem respostas inespecíficas ou inesperadas para o produto e, além disso, não sofrerem redução de peso corpóreo¹.

O TTI é denominado pelo Código de Regulamentos Federais dos Estados Unidos (US Code of Federal Regulations) como teste de segurança geral (general safety) ${ }^{2}$, pela Farmacopeia Europeia é considerado como toxicidade anormal ${ }^{3}$ e também conhecido como teste de inocuidade pela Organização Mundial da Saúde (OMS) ${ }^{4}$.

A preocupação mundial com a segurança dos produtos biológicos vem desde 1894, quando o governo alemão introduziu normas específicas para o soro antidiftérico, nas quais uma amostra de soro era considerada segura se estivesse livre de precipitação, não contivesse quaisquer impurezas bacterianas e se a concentração de fenol presente estivesse abaixo de 0,5\%. Para determinação da concentração de fenol eram realizados testes em camundongos, em que, se o produto, injetado por via subcutânea, apresentasse uma concentração de 0,5\% de fenol, o animal manifestaria apenas tremores e, caso a concentração fosse superior a $0,5 \%$, resultaria em convulsão e morte do referido animal.

Deste modo, o teste em camundongo se tornou um padrão sendo também empregado na avaliação da segurança do soro antitetânico e das primeiras vacinas bacterianas em que o fenol era utilizado como agente preservativo ${ }^{5}$.

Em 1901, em St. Louis, nos Estados Unidos da América (EUA), um lote de soro antidiftérico apresentou contaminação com toxina tetânica e 14 crianças foram a óbito. Na mesma época, um incidente similar ocorreu na Itália, culminando em 13 óbitos após o tratamento de crianças com soro antidiftérico. Em consequência, um teste com cobaio foi introduzido na Alemanha como um indicador biológico para toxinas estranhas ao produto. Esse teste foi ampliado para um teste geral de segurança a fim de detectar contaminações não específicas em produtos biológicos ${ }^{5}$.

Na Farmacopeia Brasileira, o TTI foi preconizado pela primeira vez em 1959 sob a denominação de teste de inocuidade. Nele eram utilizados somente cobaios para verificar contaminantes em vacinas contra pertussis, febre amarela, febre tifóide e varíola 6 . Em 1976, passaram a ser utilizados cobaios e camundongos para o teste na vacina antimeningocócica $A^{7}$.

Em 1994, o Instituto Paul-Ehrlich distribuiu um questionário detalhado para a maioria dos fabricantes de vacinas europeus e norte-americanos, com o objetivo de mapear os resultados do TTI5. Considerando os resultados do questionário, a Comissão da Farmacopeia Europeia, em novembro de 1995, decidiu excluir o TTI para todos os soros e vacinas veterinárias, soros hiperimunes para uso humano e imunoglobulinas, assim como vacinas combinadas com difteria, tétano e pertussis. Para todas as outras vacinas para uso humano, quando requerido o TTI, esse teste deveria ser parte da seção da monografia relativa à produção. Desse modo, as autoridades regulatórias europeias se empenharam em estabelecer estudos retrospectivos do TTI com o objetivo de se obter dados históricos que possam subsidiar alguma tomada de decisão quanto ao teste $\mathrm{e}^{8,9}$.

No Brasil, em 1996, o teste de toxicidade inespecífica foi preconizado nas normas de produção e controle de qualidade dos soros antiofídicos e das vacinas difteria, tétano e pertussis, toxóide tetânico e dupla difteria e tétano ${ }^{10,11}$.

Atualmente, na Farmacopeia Brasileira, o procedimento para verificar a toxicidade inespecífica de soros e vacinas de uso humano está incluído na monografia do teste geral de toxicidade $^{1}$. O Instituto Nacional de Controle de Qualidade em Saúde (INCQS), por ser o laboratório de controle nacional responsável pela liberação de soros hiperimunes e vacinas para uso humano no Brasil ${ }^{12}$, tem uma grande preocupação com o uso de animais de forma desnecessária buscando sempre uma tendência mundial dos princípios dos 3 Rs (redução, refinamento e substituição) ${ }^{13}$. Desta forma, o objetivo deste trabalho foi a análise retrospectiva do TTI realizado no INCQS desde 1999, avaliando quais as monografias da Farmacopeia Brasileira em que ainda é preconizado o teste ${ }^{1,14}$.

\section{MÉTODO}

Foi realizado um levantamento do número dos TTI executados no INCQS em produtos biológicos, como vacinas e soros hiperimunes, no período de 1999 a 2019. A coleta de dados dos resultados satisfatórios ou insatisfatórios, respectivamente, negativos 
ou positivos para toxicidade, foi realizada com a utilização do Harpya, um sistema de gerenciamento de amostras laboratoriais desenvolvido no INCQS, em parceria com o Programa das Nações Unidas para o Desenvolvimento (PNUD) e Agência Nacional de Vigilância Sanitária (Anvisa). Além disso, também foram analisadas todas as monografias que requerem o TTI nas $5^{\text {a }}$ e $6^{a}$ edições da Farmacopeia Brasileira. Após o levantamento, foi construída uma planilha no software MS-Exce ${ }^{\oplus}$ com todas as vacinas e soros testados e os respectivos quantitativos de ensaios realizados no período estudado.

\section{RESULTADOS E DISCUSSÃO}

Para a análise retrospectiva dos ensaios realizados no INCQS, no período de 1999 a 2012, foi selecionado um total de $3.453 \mathrm{TTI}$ realizados em 20 vacinas e 11 soros hiperimunes para uso humano (Tabela 1). Nesta seleção, todos os produtos biológicos tiveram resultados satisfatórios, considerados como aprovados ou negativos para TTI. Resultados semelhantes com a aprovação da totalidade de amostras foram observados em outros estudos retrospectivos ${ }^{8}$.

No contexto de validação de métodos analíticos, no que diz respeito ao parâmetro especificidade, verifica-se que o teste não é específico e muitos fatores podem influenciar no resultado, tais como: peso corpóreo, linhagem e nível de estresse dos animais, segundo avaliação da incerteza nos testes em animais realizados no Departamento de Farmacologia e Toxicologia do INCQS. Além disso, é obrigatório demonstrar que o teste é adequado para o uso pretendido e não é possível padronizar um controle positivo, visto que o ensaio procura por contaminação inespecífica ${ }^{15}$.

Os resultados positivos observados em vacinas podem ser devido aos ingredientes ativos ou componentes da formulação, e não uma consequência de contaminações inespecíficas ${ }^{9}, 16$. A reprodutibilidade do teste é questionável, visto que não há correlação com a qualidade do produto ou contaminação, ou seja, os mesmos lotes que apresentaram resultados positivos na TTI foram satisfatórios em retestes subsequentes ${ }^{15}$.

Atualmente, o risco de contaminações de produtos farmacêuticos com substâncias inespecíficas é significativamente baixo, visto que as indústrias são altamente reguladas quanto ao cumprimento das normas das boas práticas de fabricação (BPF) e contam com um rígido controle da qualidade durante o processo produtivo ${ }^{17,18}$.

Considerando que o teste para soros e vacinas é realizado em dois cobaios e cinco camundongos por amostra, verificou-se que foram utilizados pelo menos 6.906 cobaios e 17.265 camundongos no INCQS durante o período estudado.

Além do TTI, animais são também utilizados para teste de potência e outros testes de segurança ${ }^{1}$. Vários estudos que se utilizam de experimentação animal geralmente envolvem problemas éticos, demandam altos custo e tempo de análise, sendo alguns deles questionáveis em relação à sua relevância.

Devido ao alto quantitativo de animais utilizados para o teste de segurança de vacinas e soros, muitas agências regulatórias têm
Tabela 1. Testes de toxicidade inespecífica realizados em vacinas e soros hiperimunes no INCQS no período de 1999 a 2012.

\begin{tabular}{|c|c|c|}
\hline Produto & Período & $\begin{array}{l}\text { Número de } \\
\text { amostras }\end{array}$ \\
\hline Vacina difteria e tétano adulto & $1999-2001$ & 726 \\
\hline Vacina difteria, tétano e pertussis & $1999-2010$ & 907 \\
\hline Vacina difteria, tétano, pertussis e HIB & $2002-2011$ & 444 \\
\hline $\begin{array}{l}\text { Vacina difteria, tétano, pertussis, hepatite } \\
\text { B e HIB }\end{array}$ & $2002-2009$ & 10 \\
\hline Vacina haemophilus influenza B (HIB) & $1999-2002$ & 113 \\
\hline Vacina meningocócica C & $2002-2009$ & 30 \\
\hline Vacina meningocócica BC & $2000-2005$ & 22 \\
\hline Vacina meningocócica AC & $2009-2010$ & 14 \\
\hline Vacina febre amarela & $1999-2001$ & 160 \\
\hline Vacina febre tifoide & $2001-2006$ & 6 \\
\hline Vacina hepatite A & $2000-2006$ & 7 \\
\hline Vacina hepatite $B$ & $1999-2002$ & 243 \\
\hline Vacina influenza & $2000-2002$ & 144 \\
\hline Vacina pneumocócica & $2000-2004$ & 30 \\
\hline Vacina contra a raiva & $1999-2007$ & 197 \\
\hline Vacina contra rubéola & $1999-2000$ & 11 \\
\hline Vacina contra sarampo & $1999-2000$ & 63 \\
\hline Vacina contra varicela & $1999-2000$ & 2 \\
\hline Vacina contra sarampo e rubéola & $1999-2000$ & 101 \\
\hline Vacina contra sarampo, caxumba e rubéola & $1999-2000$ & 53 \\
\hline Soro antirrábico & $1999-2001$ & 21 \\
\hline Soro antiaracnídico & $1999-2001$ & 5 \\
\hline Soro antibotrópico & $1999-2001$ & 62 \\
\hline Soro antibotrópico-crotálico & $1999-2001$ & 5 \\
\hline Soro antibotrópico-laquético & $1999-2001$ & 6 \\
\hline Soro anticrotálico & $1999-2001$ & 23 \\
\hline Soro antidiftérico & $1999-2001$ & 4 \\
\hline Soro antielapídico & $1999-2001$ & 3 \\
\hline Soro antiescorpiônico & $1999-2001$ & 7 \\
\hline Soro antiloxoscélico & $1999-2001$ & 2 \\
\hline Soro antitetânico & $1999-2001$ & 32 \\
\hline Total & & 3.453 \\
\hline
\end{tabular}

Fonte: Elaborada pelos autores, 2020.

estimulado a implementação de métodos para reduzir, refinar ou substituir o uso de animais em testes de segurança (princípio dos 3 Rs). Quando as alternativas de substituição dos testes em animais começaram a ser tratadas na área de produtos biológicos, o TTI foi um dos primeiros ensaios destacados. Entretanto, como o objetivo do teste não é claramente definido, não teria um modelo in vitro plausível para substituí-lo, direcionando assim para a exclusão do teste ${ }^{5}$.

Com base no histórico de aprovação dos produtos, o TTI em vacinas e soros hiperimunes foi gradualmente excluído no INCQS a partir de 2001 (Tabela 2).

Em 2002, a OMS verificou que em vários países houve estudos para exclusão do TTI para muitos produtos e, nas recomendações para assegurar a qualidade, segurança e eficácia de vacinas, é preconizado que o teste pode ser omitido na liberação de 
Tabela 2. Exclusão do teste de toxicidade inespecífica no INCQS de 2001 a 2012.

\begin{tabular}{lcc}
\hline \multirow{2}{*}{ Período } & \multicolumn{2}{c}{ Quantidade de produtos excluídos } \\
\cline { 2 - 3 } & Vacinas & Soros hiperimunes \\
\hline 2001 & 5 & - \\
2002 & 2 & 11 \\
2003 & 3 & - \\
2005 & 1 & - \\
2006 & 1 & - \\
2007 & 2 & - \\
2008 & 1 & - \\
2010 & 2 & - \\
2011 & 2 & - \\
2012 & 1 & - \\
\hline Total & 20 & 11 \\
\hline
\end{tabular}

Fonte: Elaborada pelos autores, 2020.

rotina do lote final, uma vez que a consistência de produção seja demonstrada ${ }^{19}$. Quanto aos soros hiperimunes, a OMS preconiza que o TTI deve ser realizado na etapa de desenvolvimento do produto, mas está sendo gradualmente retirado em muitas normas regulatórias, visto que o teste fornece informação limitada para o controle da qualidade de um produto. A implementação correta das BPF deve fornecer evidência de que o produto cumpriria com o TTI20.

Uma norma da Food and Drug Administration de 2015 exclui o teste geral de segurança para a detecção de contaminantes tóxicos em certos produtos biológicos direcionados para a administração em humanos, vacina influenza inativada e produtos alergênicos ${ }^{21}$.

Em novembro de 1995, a Comissão da Farmacopeia Europeia decidiu excluir o TTI das monografias de vacinas para uso veterinário, assim como limitar o teste para vacinas de uso humano ${ }^{8,9}$.

Em novembro de 2017, a Comissão da Farmacopeia Europeia adotou a exclusão do TTI em 36 monografias de vacinas para uso humano, as quais tinham sido revisadas e, em janeiro de 2019, o teste foi completamente suprimido ${ }^{22}$.

Os resultados indicaram que na Farmacopeia Brasileira $5^{a}$ Edição ainda era preconizado o teste de toxicidade em sete monografias (Quadro) $)^{14}$.
Quadro. Monografias da Farmacopeia Brasileira $5^{\text {a }}$ Edição que requeriam o Teste de Toxicidade.

\begin{tabular}{|l|}
\hline Produto \\
\hline Antimoniato de meglumina solução injetável \\
Fator IX da coagulação sanguínea humana liofilizado \\
Fator VII da coagulação sanguínea humana liofilizada \\
Fibrinogênio humano liofilizado \\
Vacina difteria, tétano e pertussis \\
Vacinas para uso humano
\end{tabular}

Fonte: Elaborado pelos autores, 2020.

Apesar do INCQS ter contribuído com a Farmacopeia Brasileira para a exclusão do TTI em vacinas e soros a partir de 2002, alguns produtos biológicos não estavam no escopo, pois não eram testados no INCQS. No caso das vacinas contendo a fração pertussis celular, houve uma maior resistência na exclusão do teste, pois são vacinas que causam muitos eventos adversos. Portanto, foi mantido o TTI para as vacinas citadas na $5^{\text {a Edição }}$ da Farmacopeia Brasileira, considerando-se que no INCQS o teste foi eliminado em 2011.

$\mathrm{Na} 6^{\mathrm{a}}$ Edição, o teste só permaneceu para avaliação do Antimoniato de Meglumina solução injetável e na monografia de toxicidade nos métodos gerais ${ }^{1}$.

\section{CONCLUSÕES}

A consistência de resultados satisfatórios nos TTI no INCQS ao longo dos anos comprova que este método é questionável, visto que as vacinas contendo pertussis celular causam reações adversas em humanos mesmo aprovadas no teste ${ }^{23}$. Além disso, o requisito para o TTI leva ao uso de um grande quantitativo de animais sem justificar o benefício em demonstrar a segurança do produto, comprometendo assim a aplicação dos 3 Rs.

Várias agências regulatórias e normas internacionais têm excluído parcial ou completamente o TTI. Com base nos resultados do INCQS ao longo dos anos, o TTI em vacinas e soros hiperimunes foi excluído da Farmacopeia Brasileira e deve ser considerada a exclusão total do teste de toxicidade que ainda consta dos métodos gerais da Farmacopeia.

\section{REFERÊNCIAS}

1. Agência Nacional de Vigilância Sanitária - Anvisa. Resolução RDC N²98, de 12 de agosto de 2019. Dispõe sobre a aprovação da Farmacopeia Brasileira, $6^{a}$ edição. Diário Oficial União. 13 ago 2019.

2. US Food and Drugs Administration - FDA. Code of federal regulations: general safety: 21 food and drugs. Silver Spring: US Food and Drugs Administration; 1995.

3. Concil of Europe - CE. Abnormal toxicity. In: Concil of Europe - CE. European pharmacopoeia. 8a ed. Strasbourg: Concil of Europe; 2013. p. 184.
4. World Health Organization - WHO. Requirements for diphtheria, tetanus, pertussis and combined vaccines. In: World Health Organization - WHO. Technical report series 800 . Geneva: World Health Organization; 1990. p. 87-179.

5. Cussler K. The scientific relevance of the ATT: today and from a historical perspective. Langen: Paul Ehrlich Institute; 2015.

6. Ministério da Saúde (BR). Farmacopeia dos Estados Unidos do Brasil. 2a ed. Rio de Janeiro: Ministério da Saúde; 1959. 
7. Brasil. Decreto $N^{\circ} 78.840$, de 25 de novembro de 1976. Aprova a terceira edição da farmacopeia brasileira e dá outras providências. Diário Oficial União. 26 nov 1976.

8. Schwanig M, Nagel M, Duchow K, Kraemer B. Elimination of abnormal toxicity test for sera and certain vaccines in the european pharmacopoeia. Vaccine. 1997;15(10):1047-8. https: / /doi.org/10.1016/s0264-410x(97)00074-1

9. Duchow K, Kramer B. Abnormal toxicity: a relevant safe test under GLP- and GMP-conditions in the production of vaccines? Altex. 1994;11(5):11-8.

10. Ministério da Saúde (BR). Portaria № 174, de 11 novembro de 1996. Aprova as normas técnicas de produção e controle de qualidade dos soros antiofídicos, antitóxicos e antirrábico. Diário Oficial União. 12 nov 1996.

11. Ministério da Saúde (BR). Portaria $N^{\circ} 175$, de 11 novembro de 1996. Aprova as normas técnicas de produção e controle de qualidade das vacinas: tríplice bacteriana, toxóide tetânico, dupla, adulto, dupla infantil. Diário Oficial União. 12 nov 1996.

12. Agência Nacional de Vigilância Sanitária - Anvisa. Resolução RDC N ${ }^{\circ} 73$, de 21 de outubro de 2008. Dispõe sobre o regulamento técnico para procedimento de liberação de lotes de vacinas e soros hiperimunes heterólogos para consumo no Brasil e também para exportação. Diário Oficial União. 22 out 2008.

13. Russel WMS, Burch RL. The principles of humane experimental technique. London: Methuen; 1959.

14. Agência Nacional de Vigilância Sanitária - Anvisa. Resolução RDC No 49, de 23 de novembro de 2010. Aprova a Farmacopeia Brasileira, $5^{\mathrm{a}}$ edição e dá outras providências. Diário Oficial União. 24 nov 2010.

15. Kraemer B, Nagel M, Duchow K, Schwanig M, Cussler K. Is the abnormal toxicity test still relevant for the safety of vaccines, sera and immunoglobulins? Altex. 1996;13(1):7-16.
16. Garbe JHO, Ausborn S, Beggs C, Bopst M, Joos A, Kitashova $A A$ et al. Historical data analyses and scientific knowledge suggest complete removal of the abnormal toxicity test as a quality control test. J Pharm Sci. 2014;103(11):3349-55. https://doi.org/10.1002/jps.24125

17. Gupta RK. Is the test for abnormal toxicity, general safety or innocuity necessary for vaccines? Vaccine. 1996;14(17-18):1718. https://doi.org/10.1016/S0264-410X(96)00132-6

18. Agência Nacional de Vigilância Sanitária - Anvisa. Resolução RDC N 301, de 21 de agosto de 2019. Dispõe sobre as diretrizes gerais de boas práticas de fabricação de medicamentos. Diário Oficial União. 22 ago 2019.

19. World Health Organization - WHO. Recommendations to assure the quality, safety and efficacy of diphtheria vaccines. Geneva: World Health Organization; 2012.

20. World Health Organization - WHO. WHO Guidelines for the production, control and regulation of snake antivenom immunoglobulins. In: World Health Organization - WHO. WHO technical report series 964. Geneva: World Health Organization; 2012. p. 57-218.

21. US Food and Drugs Administration - FDA. Rules and regulations. Revocation of general safety test regulations that are duplicative of requirements in biologics license applications. Silver Springs: US Food and Drugs Administration; 2015.

22. Concil of Europe - CE. Replacement, reduction and refinement of animal testing (3Rs): latest achievements. Strasbourg: Concil of Europe; 2020[acesso 10 nov 2019]. Disponível em: https://www.edqm.eu/en/replacement-redu ction-and-refinement-animal-testing-3rs-latest-achievements

23. Ministério da Saúde (BR). Manual de vigilância epidemiológica de eventos adversos pós-vacinação. $2 a$ ed. Brasília: Ministério da Saúde; 2008.

Contribuição dos Autores

Lilia Serodio L, Caldeira C, Oliveira C, Jesus E, Moura W, Presgrave O - - Concepção, planejamento (desenho do estudo), aquisição, análise, interpretação dos dados e redação do trabalho. Todos os autores aprovaram a versão final do trabalho.

Conflito de Interesse

Os autores informam não haver qualquer potencial conflito de interesse com pares e instituições, políticos ou financeiros deste estudo.

Licença CC BY-NC atribuição não comercial. Com essa licença é permitido acessar, baixar (download), copiar, imprimir, compartilhar, reutilizar e distribuir os artigos, desde que para uso não comercial e com a citação da fonte, conferindo os devidos créditos de autoria e menção à Visa em Debate. Nesses casos, nenhuma permissão é necessária por parte dos autores ou dos editores. 